\title{
IDENTIFIKASI FAKTOR PENDUKUNG YANG BERHUBUNGAN DENGAN KEPATUHAN MINUM OBAT PADA PENDERITA HIPERTENSI DI PUSKESMAS TATELU KABUPATEN MINAHASA UTARA
}

\author{
Marsha Gladis Makatindu' ${ }^{1}$, Muhamad Nurmansyah ${ }^{2}$, Hendro Bidjuni $^{3}$ \\ ${ }^{1}$ Mahasiswa Program Studi Ilmu Keperawatan Fakultas Kedokteran Universitas Sam \\ Ratulangi, Indonesia \\ ${ }^{2,3}$ Program Studi Ilmu Keperawatan Fakultas Kedokteran Universitas Sam Ratulangi, \\ Indonesia \\ Email: marshamakatindu@gmail.com
}

\begin{abstract}
Hypertension is a disease that is not curable but it must always be controlled or controlled in order so that adherence is needed in taking medication in order to avoid complications that can lead to death. One of the factors that affect to medication adherence behavior is supporting factors. The purpose of this study was to determine the supporting factors related to medication adherence in hypertension patients at Tatelu Public Health Center, North Minahasa Regency. The research method used cross sectional approach. The respondents consisted of 71 people with sampling techniques using purposive sampling. Adherence to hypertension treatment was maesured usingModified Morisky Adherence Scale (MMAS). The results of this research using chi square statistic test at a significance level of 95\% obtained that there is a relationship between affordability of access to health service with medication adherence $(p=0.012)$, there is no relationship beetwen health insurance participation with medication adherence $(p=0.805)$ and there is a relationship between the role of health workers with medication adherence $(p=0.032)$. The Conclusion of this study indicate that the supporting factors influence medication adherence where good supporting factors can increase medication adherence in hypertension patients. Suggestions for the health services are expected to maximize the level of service and can provide additional information for hypertension patients to be more obedient in taking medication.
\end{abstract}

Keyword : hypertension, medication adherence, supporting factors.

Abstrak : Hipertensi adalah penyakit yang tidak dapat disembuhkan tetapi harus selalu dikontrol atau dikendalikan, sehingga diperlukan kepatuhan dalam minum obat agar terhindar dari komplikasi yang dapat berujung pada kematian. Salah satu faktor yang mempengaruhi perilaku kepatuhan minum obat yaitu faktor pendukung. Tujuan penelitian ini adalah untuk mengetahui faktor pendukung yang berhubungan dengan kepatuhan minum obat pada penderita hipertensi di Puskesmas Tatelu Kabupaten Minahasa Utara. Metode penelitian menggunakan pendekatan cross sectional. Responden terdiri dari 71 orang dengan teknik pengambilan sampel dengan carapurposive sampling. Pengukuran kepatuhan dilakukan dengan menggunakan kuesioner MMAS (Modified Morisky Adherence Scale). Hasil uji penelitian dengan menggunakan uji statistik chi square pada tingkat kemaknaan 95\%, didapatkan bahwa ada hubungan antara keterjangkauan akses ke pelayanan kesehatan dengan kepatuhan minum obat $(p=0,012<\alpha 0.05)$, tidak ada hubungan antara keikutsertaan asuransi kesehatan dengan kepatuhan minum obat $(p=0,805>\alpha 0.05)$ dan ada hubungan antara peran tenaga kesehatan dengan kepatuhan minum obat $(p=0,032<\alpha 0.05)$. Simpulan hasil penelitian ini menunjukkan bahwa faktor pendukung mempengaruhi kepatuhan minum obat, dimana dengan faktor pendukung yang baik dapat meningkatkan kepatuhan minum obat pada penderita hipertensi. Saran bagi pihak pelayanan kesehatan yang ada diharapkan dapat lebih memaksimalkan tingkat pelayanannya dan dapat memberikan informasi tambahan lagi bagi penderita hipertensi agar lebih patuh dalam minum obat.

Kata kunci: Hipertensi, Kepatuhan Minum Obat, Faktor Pendukung 


\section{PENDAHULUAN}

Data World Health Organization (WHO) menjelaskan bahwa setiap tahun hipertensi memberikan kontribusi hampir 9,4 juta kematian akibat penyakit kardiovaskuler. Hal ini juga meningkatkan resiko stroke sebesar 24\% (WHO, 2012). Data WHO (2015) menunjukkan 1,13 miliar orang didunia menderita hipertensi dan diiperkirakan pada tahun 2025 akan terus meningkatsebanyak $29 \%$ menjadi 1,5 miliar orang dewasa yang menderita hipertensi di dunia (Depkes, 2018). Data World Health Organization (WHO) menjelaskan bahwa $2 / 3$ orang yang menderita hipertensi berada di negara berkembang. Negara berkembang memiliki $40 \%$ penderita hipertensi sedangkan negara maju hanya $35 \%$. Hipertensi telah mengakibatkan kematian sekitar 8 juta orang setiap tahun, dimana 1,5 juta kematian terjadi di Asia Tenggara (Depkes, 2017).

Hasil Riset Kesehatan Dasar (Riskesdas) Indonesia tahun 2018 menjelaskan prevalensi hipertensi di Indonesia berdasarkan diagnosis dokter atau minum obat pada penduduk umur $\geq$ 18 tahun sebesar $8,8 \%$ dan berdasarkan hasil pengukuran sebesar $34,1 \%$.Sulawesi Utara berada di urutan 10 dengan prevalensi berdasarkan hasil pengukuran sebesar 31,7\% (Riskesdas, 2018). Di Sulawesi Utara penderita hipertensi tertinggi di Kabupaten Minahasa (54,8\%) dan terendah di Kabupaten Minahasa Selatan (10,8\%) (Profil Kesehatan Sulut, 2016). Berdasarkan data-data tersebut hanya $1 / 3$ yang terdiagnosis, sisanya $2 / 3$ tidak terdiagnosis dan hanya $0,7 \%$ orang yang terdiagnosis minum obat hipertensi.

Hipertensi dapat terjadi kapan saja dan menyerang siapa saja dari berbagai kelompok usia, kelompok sosial, maupun kelompok ekonomi, sehingga hipertensi dijuluki sebagai penyakit silent killer karena penderitanya tidak menyadari bahwa menderita hipertensi. Hipertensi tidak dapat disembuhkan tetapi harus selalu dikontrol atau dikendalikan agar tidak terjadi komplikasi yang dapat berujung pada kematian (Palmer \& William, 2007). Untuk itu diperlukan keteraturan dalam meminum obat antihipertensi agar terhindar dari komplikasi.

Obat-obat antihipertensi yang ada saat ini terbukti dapat mengontrol tekanan darah pada penderita hipertensi dan berperan dalam menurunkan resiko berkembangnya komplikasi kardiovaskular. Namun penggunaan obat antihipertensi saja tidak cukup untuk menghasilkan efek pengendalian atau pengontrolan tekanan darah jangka panjang jika tidak didukung dengan kepatuhan dalam mengkonsumsi obat antihipertensi tersebut (Saepudin et al, 2011). Hal tersebut sejalan dengan penelitian yang dilakukan oleh Hairunisa (2014) yang menyimpulkan bahwa terdapat hubungan yang signifikan antara tingkat kepatuhan minum obat antihipertensi dengan tekanan darah terkontrol $(p=0,000)$.

Kepatuhan pengobatan merupakan faktor penting dalam penatalaksanaan perawatan bagi penderita hipertensi. Masalah ketidakpatuhan sering dijumpai dalam pengobatan penyakit yang memerlukan pengobatan jangka panjang seperti hipertensi. Kepatuhan dalam pengobatan dapat diartikan sebagai perilaku pasien dalam mentaati semua nasehat dan petunjuk yang dianjurkan tenaga kesehatan. Kepatuhan didefinisikan sebagai perilaku positif penderita dalam mencapai tujuan terapi (Degresi, 2005). Ada beberapa faktor yang mempengaruhi perilaku itu sendiri salah satunya yaitu faktor pendukung.

Faktor pendukung sangat penting terutama bagi penderita hipertensi dalam menjalankan terapi pengobatan. Faktor pendukung merupakan faktor yang memungkinkan agar terjadi perilaku tertentu dimana suatu motivasi terwujud dalam lingkungan fisik yang meliputi ketersediaan fasilitas atau sarana dan prasarana kesehatan untuk mendukung 
seseorang berperilaku sehat (Notoatmodjo, 2010). Beberapa faktor pendukung yaitu keterjangkauan akses pelayanan kesehatan, asuransi kesehatan dan ketersediaan tenaga kesehatan.

Pada pengambilan data awal yang dilakukan di Puskesmas Tatelu Kabupaten Minahasa Utara, didapatkan data penderita hipertensi yang berkunjung di Puskesmas Tatelu selama bulan Agustus sampai Oktober 2020 adalah 142 orang. Dari wawancara yang didapat bahwa penderita melakukan pemeriksaan tekanan darah dan mengkonsumsi obat anti hipertensi bila gejala terasa berat. Namun bila gejalanya ringan penderita hanya istirahat saja dan tidak mengontrolkan tekanan darah serta tidak meminum obat antihipertensi. Dari hasil wawancara dapat disimpulkan bahwa penderita hipertensi tidak patuh dalam melakukan penatalaksanaan hipertensi. Ketidakpatuhan penderita hipertensi dikarenakan lupa dengan waktu kontrol kembali, tidak merasakan adanya keluhan berulang, sibuk dengan aktivitas atau pekerjaannya, dan keterjangkauan akses ke layanan kesehatan yang jauh. Berdasarkan laporan petugas kesehatan di Puskesmas Tatelu bahwa meskipun adanya asuransi kesehatan tapi beberapa penderita hipertensi tidak melakukan pengontrolan kembali. Berdasarkan uraian di atas maka peneliti tertarik untuk melakukan penelitian tentang "Identifikasi Faktor Pendukung Yang Berhubungan Dengan Kepatuhan Minum Obat Pada Penderita Hipertensi di Puskesmas Tatelu Kabupaten Minahasa Utara".

\section{METODE}

Jenis penelitian yang digunakan dalam penelitian ini adalah penelitian kuantitatif yang bersifat analitik dengan desain penelitian Cross Sectional. Penelitian ini telah dilaksanakan pada bulan Desember 2020 - Januari 2021 di Puskesmas Tatelu Kabupaten Minahasa dengan populasi penderita hipertensi berjumlah 142 orang. Teknik pengambilan sampel menggunakan purposive sampling dengan jumlah sampel yaitu 71 orang yang telah mematuhi kriteria inklusi yaitu, penderita yang terdiagnosis hipertensi dan tercatat dalam buku register rawat jalan di Puskesmas Tatelu, bersedia dijadikan sampel penelitian dengan menandatangani lembar persetujuan menjadi responden, penderita hipertensi yang mampu berkomunikasi verbal. Kriteria eksklusi yaitu penderita hipertensi yang tidak bersedia menjadi responden.

Instrumen penelitian menggunakan kuesioner yang sudah digunakan oleh Puspita (2016) tentang "Faktor-Faktor Yang berhubungan Dengan Kepatuhan Penderita Hipertensi Dalam Menjalani Pengobatan". Kuesioner ini sudah dilakukan uji validitas dengan menggunakan uji pearson product moment dimana hasil akhirnya ( $\mathrm{r}$ hasil) lebih besar dibandingkan dengan $r$ tabel. Pada tingkat kemaknaan 5\% didapat $\mathrm{r}$ tabel $=0,361$. Pada kuesioner ini $r$ hasil $>r$ tabel $(0,361)$. Hasil cronbach's alpa adalah 0,954 dengan nilai $r \alpha=0,6$. Pada kuesioner ini $r$ alpa $>r$ $\alpha$. Hasil tersebut menunjukan bahwa kuesioner ini telah valid dan reliabel untuk digunakan.

Instrumen penelitian keterjangkauan akses ke pelayanan kesehatan menggunakan kuesioner yang terdiri dari 4 item pertanyaan dengan pilihan jawaban "a" diberi skor 2 dan pilihan jawaban "b" diberi skor 1 , dengan kategori penilaian $=$ baik jika skor $\geq 6$ dan kurang jika skor $<6$. Instrumen penelitian keikutsertaan asuransi kesehatan menggunakan lembar karakteristik responden dengan jawab "ya" jika mengikuti asuransi kesehatan dan "tidak" jika tidak mengikuti asuransi kesehatan. Instrumen penelitian peran tenaga kesehatan menggunakan kuesioner yang terdiri dari 5 item pertanyaan dengan dua pilihan jawaban 'ya' diberi skor 2 dan pilihan jawaban 'tidak' diberi skor 1, dengan kategori penilaian $=$ tinggi jika skor $\geq 8$ dan rendah jika skor $<8$. Instrumen penelitian kepatuhan minum obat menggunakan kuesioner Modifed Morisky Adherence Scale (MMAS) yang 
terdiri dari 8 item pertanyaan. Pertanyaan positif dengan pilihan jawaban "ya" diberi skor 2 dan pilihan jawaban "tidak" diberi skor 1, sedangkan pertanyaan negatif dengan pilihan jawaban "ya" diberi skor 1 dan pilihan jawaban "tidak" diberi skor 2 , dengan kategori penilaian $=$ patuh jika skor $>12$ dan tidak patuh jika skor $\leq 12$.

Analisis penelitian ini menghubungkan variabel independen dan variabel dependen dengan menggunakan uji Chi Square dengan tingkat kepercayaan $95 \%$ derajat kemaknaan $\alpha=0,05$ ( $\mathrm{p}$ value $<0,05$ ).

\section{HASIL}

Hasil Penelitian ini dilakukan pada 71 responden berdasarkan karakteristik responden yaitu umur, jenis kelamin, pendidikan, pekerjaan, dan lama menderita hipertensi. Hasil analisis berdasarkan hubungan antara keterjangkauan akses ke
Penelitian ini telah dilakukan dengan memenuhi standar etika penelitian yaitu dengan menghormati harkat dan martabat manusia, menghormati privasi dan kerahasiaan subjek penelitian, keadilan dan inklusivitas atau keterbukaan, dan mempertimbangkan manfaat dan kerugian yang ditimbulkan (Setiadi, 2013). Penelitian ini juga sudah mendapatkan izin dari Puskesmas Tatelu Kabupaten Minahasa Utara dengan nomor surat 0175/000.445-PKM.TTL/II/2021.

pelayanan kesehatan, keikutsertaan asuransi kesehatan, dan peran petugas kesehatan dengan kepauhan minum obat pada penderita hipertensi di Puskesmas Tatelu Kabupaten Minahasa Utara.

\section{Karakteristik Responden}

Tabel 1. Distribusi Frekuensi Responden Berdasarkan Karakteristik Responden

\begin{tabular}{|c|c|c|}
\hline Karakteristik Responden & $\mathbf{f}$ & $\%$ \\
\hline \multicolumn{3}{|l|}{ Umur } \\
\hline - 40-50 Tahun & 23 & 32.4 \\
\hline - 51-60 Tahun & 36 & 50.7 \\
\hline$->60$ Tahun & 12 & 16.9 \\
\hline \multicolumn{3}{|l|}{ Jenis Kelamin } \\
\hline - Laki-laki & 32 & 45.1 \\
\hline - Perempuan & 39 & 54.9 \\
\hline \multicolumn{3}{|l|}{ Pendidikan } \\
\hline - Tidak Tamat SD & 7 & 9.9 \\
\hline - Tamat SD & 16 & 22.5 \\
\hline - Tamat SMP & 13 & 18.3 \\
\hline - Tamat SMA & 24 & 33.8 \\
\hline - Tamat Perguruan Tinggi & 11 & 15.5 \\
\hline \multicolumn{3}{|l|}{ Pekerjaan } \\
\hline - IRT & 18 & 25.4 \\
\hline - Pedagang & 14 & 19.7 \\
\hline - Pegawai Swasta & 12 & 16.9 \\
\hline - Pensiunan & 3 & 4.2 \\
\hline - Petani/Buruh & 17 & 23.9 \\
\hline- PNS & 7 & 9.9 \\
\hline \multicolumn{3}{|l|}{ Lama Menderita Hipertensi } \\
\hline$-<5$ Tahun & 23 & 32.4 \\
\hline$->5$ Tahun & 48 & 67.6 \\
\hline
\end{tabular}

Sumber : Data Primer, 2021 
Tabel 1. menunjukkan distribusi responden berdasarkan umur, terbanyak ada pada kategori umur 51-60 tahun yaitu sebanyak 36 responden $(50.7 \%)$. Berdasarkan jenis kelamin terbanyak yaitu perempuan sebanyak 39 (54.9\%). Berdasarkan pendidikan terakhir terbanyak yaitu Tamat SMA dengan jumlah 24 responden (33.8\%). Berdasarkan pekerjaan terbanyak yaitu sebagai ibu rumah tangga dengan jumlah 18 responden (25.4\%). Berdasarkan lama menderita hipertensi terbanyak yaitu yang menderita $>5$ tahun dengan jumlah 48 responden $(67.6 \%)$.

\section{Analisa Bivariat}

Tabel 2. Analisis Hubungan antara Keterjangkauan Akses ke Pelayanan Kesehatan Dengan Kepatuhan Minum Obat

\begin{tabular}{|c|c|c|c|c|c|c|c|}
\hline \multirow{3}{*}{$\begin{array}{c}\text { Keterjangkauan } \\
\text { Akses Ke Pelayanan } \\
\text { Kesehatan }\end{array}$} & \multicolumn{4}{|c|}{ Kepatuhan Minum Obat } & \multirow{2}{*}{\multicolumn{2}{|c|}{ Total }} & \multirow{3}{*}{$\begin{array}{c}P \\
\text { Value }\end{array}$} \\
\hline & \multicolumn{2}{|c|}{ Tidak Patuh } & \multicolumn{2}{|c|}{ Patuh } & & & \\
\hline & $\mathbf{f}$ & $\%$ & $\mathbf{f}$ & $\%$ & $\mathbf{f}$ & $\%$ & \\
\hline Kurang & 17 & 58.6 & 12 & 41.4 & 29 & 100.0 & 0.012 \\
\hline Baik & 11 & 26.2 & 31 & 73.8 & 42 & 100.0 & \\
\hline
\end{tabular}

Sumber : Data Primer, 2021

Tabel 2. menunjukkan bahwa dari 29 responden yang memiliki akses kurang sebanyak 17 responden $(58,6 \%)$ tidak patuh minum obat dan 12 responden $(41,4 \%)$ patuh minum obat, sedangkan dari
42 responden yang memiliki akses baik sebanyak 11 responden $(26,2 \%)$ tidak patuh minum obat dan 31 responden $(73,8 \%)$ patuh minum obat.

Tabel 3. Analisis Hubungan antara Keikutsertaan Asuransi Kesehatan Dengan Kepatuhan Minum Obat

\begin{tabular}{ccccccccc}
\hline \multirow{2}{*}{$\begin{array}{c}\text { Keikutsertaan } \\
\text { Asuransi Kesehatan }\end{array}$} & \multicolumn{3}{c}{ Kepatuhan Minum Obat } & & \multirow{2}{*}{ Total } & & \multirow{2}{*}{ P Value } \\
\cline { 2 - 6 } & \multicolumn{2}{c}{ Tidak Patuh } & Patuh & & & & \\
\cline { 2 - 7 } & $\mathbf{f}$ & $\mathbf{\%}$ & $\mathbf{f}$ & $\mathbf{\%}$ & $\mathbf{f}$ & $\mathbf{\%}$ & \\
\hline Tidak & 5 & 33.3 & 10 & 66.7 & 15 & 100.0 & 0.805 \\
\hline Ya & 23 & 41.1 & 33 & 58.9 & 56 & 100.0 & \\
\hline
\end{tabular}

Sumber : Data Primer, 2021

Tabel 3. menunjukkan bahwa dari 15 responden yang tidak mengikuti asuransi kesehatan sebanyak 5 responden $(33,3 \%)$ tidak patuh minum obat dan 10 responden $(66,7 \%)$ patuh minum obat, sedangkan dari
56 responden yang mengikuti asuransi kesehatan sebanyak 23 responden $(41,1 \%)$ tidak patuh minum obat dan 33 responden $(58,9 \%)$ patuh minum obat.

Tabel 4. Analisis Hubungan antara Peran Tenaga Kesehatan Dengan Kepatuhan Minum Obat

\begin{tabular}{ccccccccc}
\hline \multirow{2}{*}{$\begin{array}{c}\text { Peran Tenaga } \\
\text { Kesehatan }\end{array}$} & \multicolumn{3}{c}{ Kepatuhan Minum Obat } & & \multicolumn{2}{c}{ Total } & \multirow{2}{*}{ p-Value } \\
\cline { 2 - 6 } & \multicolumn{2}{c}{ Tidak Patuh } & \multicolumn{2}{c}{ Patuh } & & & \\
\cline { 2 - 6 } & $\mathbf{f}$ & $\mathbf{\%}$ & $\mathbf{f}$ & $\mathbf{\%}$ & $\mathbf{f}$ & $\boldsymbol{\%}$ & \\
\hline Peran Rendah & 15 & 57.7 & 11 & 42.3 & 26 & 100.0 & 0.032 \\
\hline Peran Tinggi & 13 & 28.9 & 32 & 71.1 & 45 & 100.0 & \\
\hline
\end{tabular}

Sumber : Data Primer, 2021 
Tabel 4. menunjukkan bahwa dari 26 responden yang memilih peran tenaga kesehatan rendah sebanyak 15 responden $(57,5 \%)$ tidak patuh minum obat dan 11 responden $(42,3 \%)$ patuh minum obat,

\section{PEMBAHASAN}

Hasil penelitian menunjukkan bahwa dari 29 responden yang memiliki akses kurang sebanyak 17 responden $(58,6 \%)$ tidak patuh minum obat dan 12 responden $(41,4 \%)$ patuh minum obat, sedangkan dari 42 responden yang memiliki akses baik sebanyak 11 responden $(26,2 \%)$ tidak patuh minum obat dan 31 responden $(73,8 \%)$ patuh minum obat. Hasil analisis menunjukkan bahwa keterjangkauan akses ke pelayanan kesehatan dengan kepatuhan minum obat memiliki nilai $\mathrm{p}$-value 0,012 . Dimana nilai $\mathrm{p}$-value $<0,05$ yang berarti bahwa ada hubungan antara keterjangkauan akses pelayanan kesehatan dengan kepatuhan minum obat pada penderita hipertensi.

Niven (2002) menyatakan bahwa salah satu faktor yang mempengaruhi kepatuhan berobat adalah faktor pendukung seperti tersedianya suatu fasilitas kesehatan dan terjangkaunya akses ke fasilitas kesehatan tersebut. Hal ini dibuktikan dengan hasil penelitian bahwa akses ke pelayanan yang baik lebih banyak dibandingkan akses ke pelayanan yang kurang. Hasil penelitian ini menunjukkan bahwa akses yang baik lebih banyak responden yang patuh daripada responden yang tidak patuh. Hal tersebut terjadi karena keterjangkauan Akses ke pelayanan kesehatan yang baik adalah akses yang dapat dijangkau dengan mudah oleh seluruh masyarakat.

Faktor keterjangkauan jarak atau kemudahan dalam menuju tempat tujuan (fasilitas kesehatan) merupakan hal yang sangat penting dalam upaya mendukung seseorang dalam menjalankan kepatuhan pengobatan (Bahri, 2013).Keterjangkauan akses dapat dilihat dari segi jarak, waktu tempuh dan kemudahan transportasi untuk mencapai pelayanan kesehatan (Puspita, 2016). Keterjangkauan akses sedangkan dari 45 responden yang memilih peran tenaga kesehatan tinggi sebanyak 13 responden $(28,9 \%)$ tidak patuh minum obat dan 32 responden $(71,1 \%)$ patuh minum obat.

memungkinkan penderita akan semakin patuh dalam menjalani pengobatan. Semakin jauh jarak rumah penderita dari tempat pelayanan kesehatan dan sulitnya transportasi maka akan berhubungan dengan kepatuhan pengobatan.

Hasil penelitian menunjukkan bahwa dari 15 responden yang tidak mengikuti asuransi kesehatan sebanyak 5 responden $(33,3 \%)$ tidak patuh minum obat dan 10 responden $(66,7 \%)$ patuh minum obat, sedangkan dari 56 responden yang mengikuti asuransi kesehatan sebanyak 23 responden $(41,1 \%)$ tidak patuh minum obat dan 33 responden $(58,9 \%)$ patuh minum obat. Hasil analisis menunjukkan bahwa keikutsertaan asuransi kesehatan dengan kepatuhan minum obat memiliki nilai $\mathrm{p}$ value 0,805 . Dimana nilai $p$-value $>0,05$ yang berarti bahwa tidak ada hubungan antarakeikutsertaan asuransi kesehatan dengan kepatuhan minum obat pada penderita hipertensi.

Hasil penelitian ini menunjukkan bahwa tidak ada hubungan antara keikutsertaan asuransi kesehatan dengan kepatuhan minum obat respoden. Hal ini disebabkan karena meskipun tidak mengikuti asuransi kesehatan lebih banyak responden yang patuh dari pada responden yang tidak patuh. Sebaliknya responden yang mengikuti asuransi kesehatan sebagian tidak patuh dengan pengobatan. Hal inilah yang menyebabkan tidak adanya perbedaan hasil penelitian antara yang mengikuti asuransi kesehatan dan yang tidak mengikuti asuransi kesehatan.

Hasil penelitian ini sejalan dengan penelitian Puspita (2016) dimana tidak ada hubungan antara keikutsertaan asuransi kesehatan dengan kepatuhan dalam menjalani pengobatan, karena baik pasien yang mengikuti asuransi kesehatan maupun tidak mengikuti asuransi 
kesehatan, sama-sama tidak dikenakan biaya untuk berobat. Faktor biaya memiliki peranan yang penting yang dapat mempengaruhi kepatuhan pasien hipertensi dalam melakukan pengobatan (Pujiyanto, 2008). Dengan adanya keringan dalam pembiayaan maka pasien tetap patuh dalam pengobatan meskipun tidak mengikuti asuransi kesehatan.

Hasil penelitia menunjukkan bahwa dari 26 responden yang memilih peran tenaga kesehatan rendah sebanyak 15 responden $(57,5 \%)$ tidak patuh minum obat dan 11 responden $(42,3 \%)$ patuh minum obat, sedangkan dari 45 responden yang memilih peran tenaga kesehatan tinggi sebanyak 13 responden $(28,9 \%)$ tidak patuh minum obat dan 32 responden $(71,1 \%)$ patuh minum obat. Hasil analisis menunjukkan bahwa peran tenaga kesehatan dengan kepatuhan minum obat memiliki nilai $\mathrm{p}$-value 0,032 . Dimana nilai p-value $<0,05$ yang berarti bahwa ada hubungan antara peran tenaga kesehatan dengan kepatuhan minum obat pada penderita hipertensi.

Menurut teori Lawrance Green, peran petugas kesehatan merupakan faktor pendorong (reinforcing factor) yang berhubungan dengan perilaku kepatuhan berobat yang berupa sikap dan perilaku petugas kesehatan yang mendukung penderita untuk patuh berobat (Notoatmodjo, 2007). Teori ini sesuai dengan hasil penelitian bahwa terdapat hubungan antara peran petugas kesehatan dengan kepatuhan berobat. Hal ini terjadi karena sebagian responden menyatakan bahwa terdapat pelayanan yang baik yang mereka terima dari petugas kesehatan, sehingga terjadi perilaku positif dari penderita untuk patuh minum obat. Hal ini dibuktikan dengan hasil penelitian bahwa peran petugas yang baik lebih tinggi dibandingkan peran petugas kesehatan yang rendah.

Dukungan petugas kesehatan sangat penting bagi penderita karena sebagian informasi mengenai penyakit yang diperoleh adalah dari petugas kesehatan.
Dukungan petugas kesehatan berupa pemberian informasi, pelayanan yang baik dan sikap selama proses pelayanan (Pratama \& Ariastuti, 2015). Perilaku petugas kesehatan yang memberikan pelayanan yang baik, ramah serta memberikan penjelasan tentang penyakit yang diderita dan penjelasan minum obat yang teratur memungkinkan penderita untuk patuh dalam pengobatan, sehingga tekanan darah berada pada rentang yang normal dan komplikasi akibat hipertensi dapat dicegah dan dikontrol.

\section{SIMPULAN}

Berdasarkan hasil penelitian ditemukan $39,4 \%$ responden tidak patuh dalam minum obat, dimana perempuan lebih banyak tidak patuh dibandingkan laki-laki. Rendahnya tingkat pendidikan dan lama menderita hipertensi $>5$ tahun juga membuat penderita tidak patuh dalam minum obat, sehingga didapatkan hasil yaitu ada hubungan antara keterjangkauan akses ke pelayanan kesehatan dengan kepatuhan minum obat, tidak ada hubungan antara keikutsertaan asuransi kesehatan dengan kepatuhan minum obat dan ada hubungan antara peran tenaga kesehatan dengan kepatuhan minum obat.

\section{DAFTAR PUSTAKA}

Bahri, Saiful. (2013). Faktor-faktor yang Berpengaruh Terhadap Kepatuhan Penderita Hipertensi Dalam Menjaga Tekanan Darah di Wilayah Kerja Puskesmas Pandanarum Kabupaten Banjarnegara. Diakses: 21 September 2020.

http://repository.ump.ac.id/5598/

Degresi. (2005). Ilmu Perilaku Manusia. Jakarta : Rineka Cipta.

Departemen Kesehatan Republik Indonesia. (2017). Sebagian Besar Penderita Hipertensi tidak Menyadarinya. Diakses : 18 September 2020 https://www.kemkes.go.id/article/vie w/17051800002/sebagian-besarpenderita-hipertensi-tidak$\underline{\text { menyadarinya.html }}$ 
Departemen Kesehatan Republik Indonesia. (2018). Hipertensi Membunuh Diam-diam, Ketahui Tekanan Darah Anda. Diakses : 18 September 2020 https://sehatnegeriku.kemkes.go.id/ba ca/umum/20180516/5625911/hiperte nsi-membunuh-diam-diam-ketahuitekanan-darah/

Djuhaeni, Henni. (2007). Asuransi Kesehatan dan Managed Care. Universitas Padjadjaran: Bandung.

Gama, I.K., Saemidi, I.W., Harini, I.G.A. (2014). Faktor Penyebab Ketidakpatuhan Kontrol Penderita Hipertensi. Diakses : 10 Januari 2021 http://poltekkesdenpasar.ac.id/files/JURNAL\%20GE MA\%20KEPERAWATAN/DESEM BER\%202014/ARTIKEL\%20I\%20K etut\%20Gama\%20dkk, \%202.pdf

Hairunisa. (2014). Hubungan Tingkat Kepatuhan Minum Obat dan Diet dengan Tekanan Darah Terkontrol Pada Penderita Hipertensi Lansia di Wilayah Kerja Puskesmas Perumnas I Kecamatan Pontianak Barat. Diakses: 2 Oktober 2020 https://media.neliti.com/media/public ations/189138-ID-hubungan-tingkatkepatuhan-minum-obat-da.pdf

Martiningsih U, Rachmadi F, Fahdi F. (2018). Hubungan Peran Petugas Kesehatan Terhadap Kepatuhan Minum Obat Antihipertensi pada Penderita Hipertensi di Wilayah Kerja Puskesmas Parit H. Husin II Kota Pontianak. Diakses: 22 September 2020 https://jurnal.untan.ac.id/index.php/j mkeperawatanFK/article/view/29496 175676579081

Maryanti Rizki. (2017). Hubungan Kepatuhan Minum Obat Terhadap Peningkatan Tekanan Darah Pada Penderita Hipertensi (Studi di Desa Plandi Dsn Parimono Kec. Jelakombo Kab. Jombang). Diakses: 22 September 2020 http://repo.stikesicme-
jbg.ac.id/269/1/Skripsi\%20RIzki\%20 M.pdf

Niven.(2002). Psikologi kesehatan pengantar untuk perawat profesional kesehatan lain. Jakarta : EGC.

Notoadmojo. (2010). Metodologi Penelitian Kesehatan. Jakarta : Rineka Cipta

Novian \& Arista. (2013) Kepatuhan Diit Pasien Hipertensi. Jurnal Kesehatan Masyarakat Vol.9, No.1, Juli 2013, Hal 100-105.

Palmer, A., Williams, B. Simple Guide, (2007). Tekanan Darah Tinggi. (Yasmine, Penerjemah). Jakarta : Erlangga.

Pratama G. W., Ariastuti P. (2015). Faktorfaktor yang Mempengaruhi Kepatuhan Pengobatan Hipertensi Pada Lansia Binaan Puskesmas Klungkung 1. Diakses : 18 September 2020. https://ojs.unud.ac.id/index.php/eum/ article/view/19735

Puspita Exa. (2016). Faktor-faktor yang Berhubungan dengan Kepatuhan Berobat pada Penderita Hipertensi dalam Menjalani Pengobatan di Puskesmas Gunungpati Kota Semarang. Diakses: 15 September 2020.

http://lib.unnes.ac.id/23134/1/641141 1036.pdf

Riset Kesehatan Dasar. (2018). Badan Penelitian dan Pengembangan Kesehatan. Kementrian Kesehatan RI.

Saepudin M. (2011). Kepatuhan Penggunaan Obat pada Pasien Hipertensi di Puskesmas. Vol 6, No 4, Juli 2013, ISSN: 1412-1107, Hal 246-253.

Setiadi. (2013). Konsep dan Praktik Penulisan Riset Keperawatan. Yogyakarta : Graha Ilmu

Tim Bumi Medika. (2017). Berdamai dengan HIPERTENSI. Jakarta : Bumi Medika

World Health Organization (WHO). (212). Report of Hypertension. Geneva. 